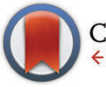

CrossMark \&lick for updates

Cite this: Chem. Commun., 2015, 51,14060

Received 17th May 2015

Accepted 31st July 2015

DOI: $10.1039 / \mathrm{c5cc04069h}$

www.rsc.org/chemcomm

\section{Blue-green emissive cationic iridium(III) complexes using partially saturated strongly-donating guanidyl-pyridine/-pyrazine ancillary ligands $\dagger$}

\author{
Kamrul Hasan, ${ }^{a}$ Amlan K. Pal, ${ }^{a}$ Thomas Auvray, ${ }^{a}$ Eli Zysman-Colman*b and \\ Garry S. Hanan ${ }^{\star a}$
}

A new class of cationic iridium(III) complexes of the form $\left[\left(C^{\wedge} N\right)_{2} \mid r-\right.$ $\left.\left(N^{\wedge} N\right)\right]\left[P F_{6}\right]$ is reported, where $C^{\wedge} N=$ cyclometallating 2-phenylpyridinato, ppy, or 2-(2,4-difluorophenyl)-5'-methylpyridinato, dFMeppy, and $\mathrm{N}^{\wedge} \mathrm{N}=$ guanidyl-pyridine, gpy, or -pyrazine, gpz, as the ancillary ligand. A large blue-shift in the emission coupled with a 7-to-9 fold enhancement in photoluminescence quantum yield and microsecond emission lifetimes were observed for the complexes containing the partially saturated gpy ligand as compared to the benchmark complex $\left[(p p y)_{2} \operatorname{Ir}\left(b_{p p y}\right)\right]\left[P_{6}\right], C 1$, where bpy is $2,2^{\prime}$-bipyridine.

Cationic iridium(III) complexes are the subject of tremendous recent interest due to their use as photophysically active materials in a wide assortment of applications, e.g., lighting devices, ${ }^{1}$ solar energy harvesters, ${ }^{2}$ in sensing or bioimaging ${ }^{3}$ and photosensitizers for hydrogen production from water. ${ }^{4}$ Generally, the photophysical properties of these complexes can be finely tuned through concomitant modification of the cyclometallating and ancillary ligands. In particular, replacing the $2,2^{\prime}$-bipyridine (bpy) in the archetypal $\left[(\mathrm{ppy})_{2} \operatorname{Ir}(\mathrm{bpy})\right]\left[\mathrm{PF}_{6}\right], \mathbf{C 1}$, with other bidentate heterocyclic ligands has proven to be very effective in modulating the emission energy (ppy $=2$-phenylpyridinato). For instance, complexes bearing phenanthroline- $-{ }^{5 a}$ imidazole- $-{ }^{5 b} 1,2,3$-triazole- $-{ }^{5 c}$ tetrazole ${ }^{5 d}$ and pyrazole $^{5 e}$-based ancillary ligands have all been investigated. ${ }^{5 f}$ To the best of our knowledge partially saturated, strongly-donating neutral $N, N^{\prime}$-bidentate heterocycles have not been explored as ancillary ligands with iridium(III) complexes. Very recently multi-dentate guanidyl-based ligands and their ruthenium

\footnotetext{
${ }^{a}$ Département de Chimie, Université de Montréal, 2900 Edouard-Montpetit, Montréal, Québec H3T-1J4, Canada. E-mail: garry.hanan@umontreal.ca; Fax: +1 514 343-2468; Tel: +1 514 343-7056

${ }^{b}$ Organic Semiconductor Centre, EaStCHEM School of Chemistry,

University of St Andrews, St Andrews, Fife, KY16 9ST, UK.

E-mail: eli.zysman-colman@st-andrews.ac.uk; Web: http://www.zysman-colman.com;

Fax: +44 (0)1334 463808; Tel: +44 (0)1334 463826

$\dagger$ Electronic supplementary information (ESI) available. CCDC 1015124. For ESI and crystallographic data in CIF or other electronic format see DOI: 10.1039/ c5cc04069h
}

complexes have been studied by the Hanan group. ${ }^{6}$ The incorporation of strongly donating $\mathrm{H}$-hpp (where H-hpp $=1,3,4,6,7,8$ hexahydro-2H-pyrimido[1,2-a]pyrimidine or commonly known as guanidine in this work) moieties into $\mathrm{N}$-heterocycles by means of $\mathrm{C}-\mathrm{N}$ bond-forming reactions gave rise to electron-rich bidentate or tridentate chelates. ${ }^{7}$ These ligands conferred large red-shifts of between $120-270 \mathrm{~nm}$ of the lowest triplet energy metal-to-ligand charge-transfer, ${ }^{3} \mathrm{MLCT}$, emission band of their Ru(II)-complexes as compared to $\left[\mathrm{Ru}(\mathrm{bpy})_{3}\right]^{2+}$ and $\left[\mathrm{Ru}(\text { tpy })_{2}\right]^{2+}$ (tpy $=2,2^{\prime}: 6^{\prime}, 2^{\prime \prime}$ terpyridine). ${ }^{6}$ Herein, we present the first three examples of cationic iridium(III) complexes that incorporate neutral bidentate 2-guanidylpyridine, gpy, and 2-guanidylpyrazine, gpz, as the ancillary ligand (Scheme 1) and contrast their photophysical properties to those of C1. The observed optoelectronic properties align with the density functional theory (DFT) and time-dependant DFT (TD-DFT) studies (vide infra).

The gpy and gpz ligands were synthesized in high yields (95\% and $82 \%$ ) according to the literature. ${ }^{6 a}$ These ligands were

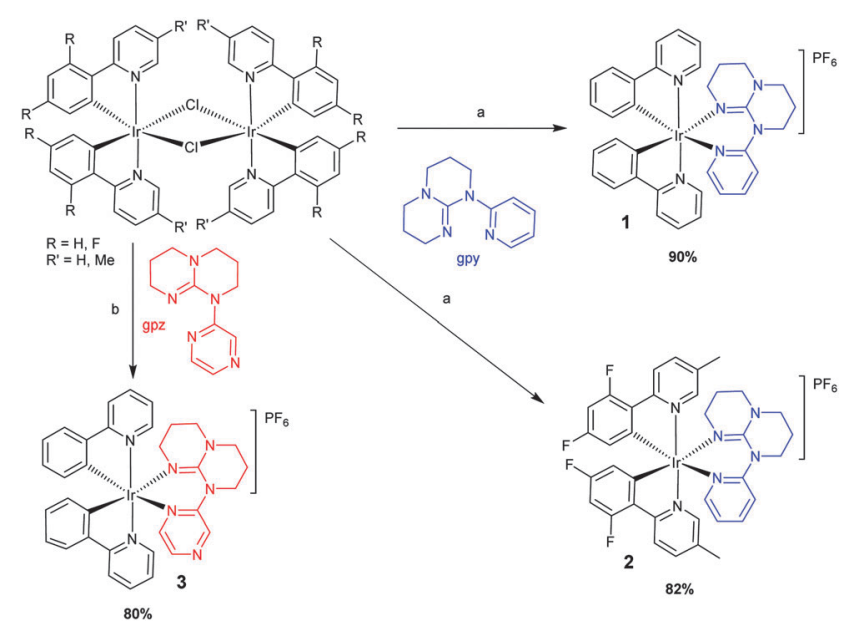

Scheme 1 Syntheses of $1-3$ (a) i. 2.1 equiv. gpy in $\mathrm{DCM} / \mathrm{MeOH}(1: 1)$, $50{ }^{\circ} \mathrm{C}, 19$ h; ii. $\mathrm{NH}_{4} \mathrm{PF}_{6}$ (aq). (b) i. 2.1 equiv. gpz in $\mathrm{DCM} / \mathrm{MeOH}(1: 1)$, $50{ }^{\circ} \mathrm{C}, 19$ h; ii. $\mathrm{NH}_{4} \mathrm{PF}_{6}$ (aq). 
used to cleave $\left[(\text { ppy })_{2} \operatorname{Ir}(\mu-\mathrm{Cl})\right]_{2}$ and $\left[(\mathrm{dFMeppy})_{2} \operatorname{Ir}(\mu-\mathrm{Cl})\right]_{2}$ (dFMeppy $=$ 2-(2,4-difluorophenyl)-5-methylpyridinato) and complexes 1-3 were obtained in high yield (80-90\%) following an anion metathesis with aq. $\mathrm{NH}_{4} \mathrm{PF}_{6}$ (Scheme 1). They were fully characterized by ${ }^{1} \mathrm{H}$-, ${ }^{13} \mathrm{C}$-, ${ }^{19} \mathrm{~F}$-NMR spectroscopy, melting point and HR-MS analyses (Fig. S1-S11 in ESI $\dagger$ ). Resonances in the ${ }^{1} \mathrm{H}$ NMR spectra of 1-3 corresponding to the saturated aliphatic backbone of the ancillary ligand were observed between 1 to $4 \mathrm{ppm}$ as found in other complexes with saturated ligands. ${ }^{8}$ The splitting of the methylene protons suggest that they are diastereotopic as also observed for analogous Ru complexes. ${ }^{6 b-e}$

Crystals of 3 suitable for X-ray structural determination were grown by slow evaporation from a mixture of DCM and diisopropylether $(1: 1, \mathrm{v} / \mathrm{v})$ (Fig. 1). Selected crystallographic parameters are tabulated in Table S1 (ESI $\dagger$ ). Selected bond distances and angles are in Table S2 (ESI $\dagger$ ). The $\operatorname{Ir}(\mathrm{III})$-ion is coordinatively saturated and in a distorted octahedral geometry. The $\mathrm{C}^{\wedge} \mathrm{N}$ carbon atoms are found to be mutually cis disposed, similar to the solid-state structure of C1 (CCDC 745138). ${ }^{9}$ The average Ir- $\mathrm{C}_{\mathrm{ppy}}(2.005(10) \AA)$ and Ir- $\mathrm{N}_{\mathrm{ppy}}(2.054(8) \AA)$ bond lengths are similar to those in C1 [Ir- $\mathrm{C}_{\text {ppy }}(2.013(3) \AA)$; Ir- $\mathrm{N}_{\text {ppy }}(2.045(3) \AA)$ ] The $\mathrm{N}_{\mathrm{N}^{\wedge} \mathrm{N}}-\mathrm{Ir}-\mathrm{N}_{\mathrm{N}^{\wedge} \mathrm{N}}$ bite angle $\left(83.8(3)^{\circ}\right)$ of the gpz is wider than when bpy is the ancillary ligand in $\mathbf{C 1}, 76.2(1)^{\circ}$ due to formation of a six-membered chelate ring present in 3.

The UV-visible absorption spectra of 1-3 are shown in Fig. S12 (ESI $\dagger$ ) and calculated molar absorptivities are reported in Table S3 (ESI $\dagger$ ). The absorption profiles are similar to other heteroleptic cationic iridium(III) complexes reported in the literature. ${ }^{10}$ TD-DFT studies assign the bands below $300 \mathrm{~nm}$ as predominantly ligand-centred spin allowed $\pi-\pi^{*}$ transitions from both ligands with minor contributions from ${ }^{1} \mathrm{MLCT}$ and ${ }^{1}$ LLCT $\left({ }^{1}\right.$ MLCT $=$ singlet metal-to-ligand charge transfer and ${ }^{1}$ LLCT $=$ singlet ligand-to-ligand charge transfer). ${ }^{11}$ The absorption bands in the 300-450 $\mathrm{nm}$ region are mainly mixed spin-allowed CT transitions (for relative contributions see Tables S5-S7, ESI $\dagger$ ) with non-negligible contribution from ligand-centred transitions. The lowest energy absorption bands in 1-3 are slightly red-shifted by $23-41 \mathrm{~nm}$ compared to $\mathbf{C} \mathbf{1}(420 \mathrm{~nm})$ in an analogous manner to the trend observed with $\left[(\mathrm{bpy})_{2} \mathrm{Ru}(\mathrm{gpy} / \mathrm{gpz})\right]^{+2}$ vs. reference

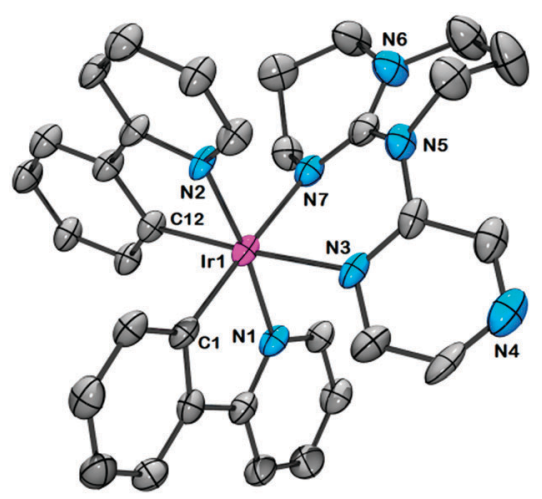

Fig. 1 ORTEP view of complex 3 . Hydrogen atoms, an anion and a solvated dichloromethane molecule have been omitted for clarity. Ellipsoids correspond to a $50 \%$ probability level.

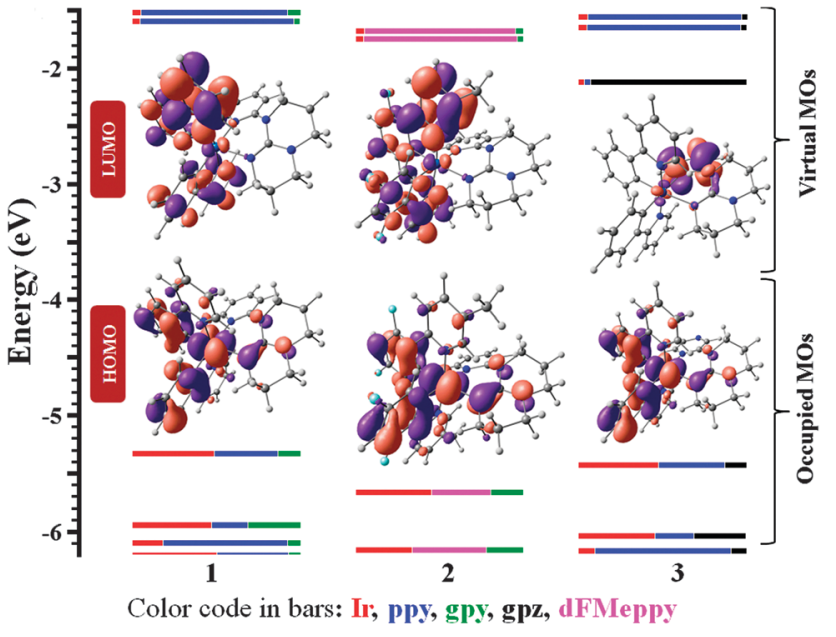

Fig. 2 Calculated frontier MO energies of 1-3, obtained from TD-DFT [(rb3lyp/LanL2DZ(f) for Ir(III)) and (6-31g** for $\mathrm{C}, \mathrm{H}, \mathrm{N},(\mathrm{F}))]$ with $\mathrm{CPCM}\left(\mathrm{CH}_{3} \mathrm{CN}\right)$ and $0.5 \mathrm{eV}$ threshold of degeneracy. Kohn-Sham MOs of 1, $\mathbf{2}$ and $\mathbf{3}$ are also shown (contours isovalue: 0.03 ).

$\left[\mathrm{Ru}(\mathrm{bpy})_{3}\right]^{+2}{ }^{6 a}$ The red-shift in the absorption spectra of 1-3 is due to a destabilization of the metal/ $\mathrm{C}^{\wedge} \mathrm{N}$-localized HOMO as a result of increased electron density on the iridium conferred by the electron-donating gpy ligand (HOMO = highest occupied molecular orbital, Tables S8-S10 and Fig. S15, ESI $\dagger$ ). The decreasing optical gap (inset figure of Fig. S12, ESI $\dagger$ ) from 2 to 1 to 3 aligns with the computed HOMO-LUMO (LUMO = lowest unoccupied molecular orbital) energy gap ( $\Delta E$ of $2=3.91 \mathrm{eV} ; \Delta E$ of $\mathbf{1}=3.72 \mathrm{eV} ; \Delta E$ of $3=3.31 \mathrm{eV}$ ) (Fig. 2 and Table S3, ESI $\dagger$ ).

The electrochemical behaviour of 1-3 was monitored by cyclic voltammetry (CV) and the CV traces in deaerated MeCN containing $0.1 \mathrm{M} n-\mathrm{Bu}_{4} \mathrm{NPF}_{6}$ as the supporting electrolyte and using $\mathrm{Fc} / \mathrm{Fc}^{+}$as an internal standard at $298 \mathrm{~K}$ are shown in Fig. S13 and S14 (ESI $\dagger)$. The detailed $\mathrm{CV}$ data $v s$. SCE $\left(\mathrm{Fc} / \mathrm{Fc}^{+}=\right.$ $0.38 \mathrm{~V}$ in $\mathrm{MeCN})^{12}$ are summarized in Table S4 (ESI $\dagger$ ) while only first redox potentials are listed in Table 1. In the anodic scan, all of the complexes showed three successive oxidation waves, the first quasi-reversible and the other two irreversible. The first oxidation wave of 1-3 falls between 0.99 to $1.21 \mathrm{~V}$ (Fig. S14, $\mathrm{ESI} \dagger$ ) and is assigned to the $\mathrm{Ir}^{\mathrm{III} / \mathrm{IV}}$ redox couple with contributions from the $\mathrm{C}^{\wedge} \mathrm{N}$ ligands. ${ }^{5 f}$ These oxidation potentials are cathodically shifted to a significant extent compared to other heteroleptic iridium(III) cationic complexes bearing similar $\mathrm{C}^{\wedge} \mathrm{N}$ ligands, $\left.\left(\mathbf{C} 1: E_{\mathrm{ox}}^{1 / 2}=1.27 \mathrm{~V} \text { vs. SCE; [(dFMeppy }\right)_{2} \operatorname{Ir}(\mathrm{bpy})\right]\left[\mathrm{PF}_{6}\right], \mathbf{C} 2$ : $E_{\mathrm{Ox}}^{1 / 2}=1.55 \mathrm{~V}$ vs. SCE). Indeed, DFT calculations show that the HOMOs of 1-3 are constituted almost equally with iridium and the $\mathrm{C}^{\wedge} \mathrm{N}$ ligands with a progressive increase in the calculated energy of the HOMO of $2\left(E_{\text {Hомо }}=-5.66 \mathrm{eV}\right)$ to $3\left(E_{\text {Hомо }}=\right.$ $-5.43 \mathrm{eV})$ to $1\left(E_{\mathrm{HOMO}}=-5.32 \mathrm{eV}\right)$, which is in excellent agreement with experiment. The first oxidation potential of $2\left(E_{\mathrm{ox}}^{1 / 2}=\right.$ $1.21 \mathrm{~V})$ is more positive compared to that of $1\left(E_{\mathrm{ox}}^{1 / 2}=0.99 \mathrm{~V}\right)$ due to the electron withdrawing fluorine atoms on the $\mathrm{C}^{\wedge} \mathrm{N}$ ligands, which increase the stability of HOMOs. The $E_{\mathrm{ox}}^{1 / 2}$ of 3 is slightly more positive $(1.04 \mathrm{~V})$ compared to that of 1 , although both contain the same cyclometallating ppy ligand. This is due to 
Table 1 Optoelectronic properties of 1-3 in degassed $\mathrm{MeCN}^{a}$

\begin{tabular}{lllllcll}
\hline & & & & $\begin{array}{l}E_{1 / 2}^{1 \text { ox }} / \mathrm{V} \\
\left(\Delta E_{\mathrm{p}}, \mathrm{mV}\right)\end{array}$ & $\begin{array}{l}E_{1 / 2}^{1 \mathrm{red}} / \mathrm{V} \\
\left(\Delta E_{\mathrm{p}}, \mathrm{mV}\right)\end{array}$ \\
\hline $\mathbf{1}$ & 503 & 60 & 2.1 & 2.9 & 1.9 & $0.99(88)$ & -2.13 \\
$\mathbf{2}$ & 470,498 & 62 & 2.6 & 2.3 & 1.4 & $1.21(72)$ & -2.12 \\
$\mathbf{3}$ & 640 & 0.2 & 0.02 & 1.0 & 499 & $1.04(92)$ & $-1.60(95)$
\end{tabular}

${ }^{a} \Phi_{\mathrm{PL}}$ was measured at $298 \mathrm{~K}$ using quinine sulfate $\left(\Phi_{\mathrm{PL}}=54 \%\right.$, in $0.5 \mathrm{~N}$ $\left.\mathrm{H}_{2} \mathrm{SO}_{4}\right)$ as in ref. 16. $k_{\mathrm{r}}=\Phi / \tau$ and $k_{\mathrm{nr}}=(1-\Phi) / \tau$. CV values are in $\mathrm{V} v s$. SCE. ${ }^{9} \Delta E_{\mathrm{p}}=\left|E_{\mathrm{pa}}-E_{\mathrm{pc}}\right|$, where $E_{\mathrm{pa}}=$ anodic peak potential and $E_{\mathrm{pc}}=$ cathodic peak potential; $E_{1 / 2}=\left(E_{\mathrm{pa}}+E_{\mathrm{pc}}\right) / 2$ and result from one-electron processes. A non-aqueous Ag/ $\mathrm{Ag}^{+}$electrode (silver wire in a solution of $0.1 \mathrm{M} \mathrm{AgNO}_{3}$ in $\mathrm{MeCN}$ ) was used as the pseudoreference electrode; a glassy-carbon electrode was used for the working electrode and a Pt electrode was used as the counter electrode.

modulating influence of the less electron-donating gpz ligand. Overall, the trends observed in the electrochemistry are entirely consistent with those in the electronic spectroscopy.

Upon scanning to negative potential, 1 and 2 show three successive one-electron irreversible reduction-waves whereas complex 3 shows a first quasi-reversible one-electron reduction followed by two irreversible one-electron reduction events (Fig. S13 and Table S4, ESI $\dagger$ ). The first of the reduction waves falls between -2.12 to $-1.60 \mathrm{~V}$, which are more cathodically shifted compared to benchmark complexes $\mathbf{C} 1$ and $\mathbf{C} 2$ (C1: $E_{\text {red }}^{1 / 2}=$ $-1.38 \mathrm{~V} ; \mathbf{C 2}: E_{\text {red }}^{1 / 2}=-1.34 \mathrm{~V}$ ). The more negative reduction potentials in 1-3 are the result of the strongly electron-donating guanidyl moiety. Similar effects were previously observed for more electron rich ancillary ligands $\left(\mathrm{N}^{\wedge} \mathrm{N}\right)$. For instance, the first reduction waves of $\left[(\mathrm{ppy})_{2} \operatorname{Ir}(\mathrm{btl})\right] \mathrm{PF}_{6}{ }^{13 a}$ and $\left[(\mathrm{ppy})_{2} \mathrm{Ir}-\right.$ (4-pytl) $\mathrm{PF}_{6}{ }^{13 b}$ were found, respectively, at -1.99 and $-2.25 \mathrm{~V}$ vs. $\operatorname{SCE}\left(\right.$ btl $=1,1^{\prime}$-benzyl-4,4'-bi-1H-1,2,3-triazolyl and 4-pytl = 4-methyl-3-(pyridin-2-yl)-1,2,4-triazole). In the case of complexes $\left[(\mathrm{dFppy})_{2} \operatorname{Ir}(3-\mathrm{pytl})\right]^{14 a}$ and $\left[(\mathrm{Fphtl})_{2} \operatorname{Ir}(3-\mathrm{pytlph})\right] \mathrm{PF}_{6}{ }^{14 b}$ (where 3-pytl = 2-(1,2,3-triazol-5-yl)pyridine, Fphtl = 1-benzyl-4-(4-fluorophenyl)-1H-1,2,3-triazole and 3-pytlph = 2-(1-phenyl-1,2,3-triazol-4yl)pyridine, respectively) the reduction waves were observed at -2.39 and $-1.76 \mathrm{~V} v$ s. SCE. In our case, the first reduction waves of 1 and 2 are almost identical at -2.13 and $-2.12 \mathrm{~V}$, respectively, as indeed both complexes have the same gpy ancillary ligand. On the other hand, the first reduction wave of 3 is at $-1.60 \mathrm{~V}$ with gpz as the ancillary ligand. The $\sigma$-donating effect is mitigated in 3 due to the presence of the extra inductively electron-withdrawing nitrogen atom in the pyrazine, resulting in a dramatic anodic shift of $c a .500 \mathrm{mV}$ of the first reduction potential compared to those of $\mathbf{1}$ and 2. The CVs and the DFT calculations demonstrate that the LUMOs of 1 and 2 reside mainly on the $\mathrm{C}^{\wedge} \mathrm{N}$ ligands whereas in 3 it is localized on the pyrazine (Tables S8-S10 and Fig. S15, ESI $\dagger$ ). In 1 and 2, the absorption band for the HOMOLUMO is predominantly ppy $\pi-\pi^{*}$ in nature while for 3 it is mixed $\mathrm{CT}$, i.e., the LUMO is different in both cases.

The steady-state emission spectra of 1-3 were recorded in degassed MeCN at $298 \mathrm{~K}$ and are shown in Fig. 3. The photophysical data are summarized in Table 1 . The emission spectra for $\mathbf{1}$ and $\mathbf{3}$ are broad and featureless, indicative of mixed ${ }^{3} \mathrm{CT}$ emission while the spectrum of 2 is structured, pointing to significant ${ }^{3}$ LC-based emission. TD-DFT calculations (Fig. S16-S18, ESI $\dagger$ )

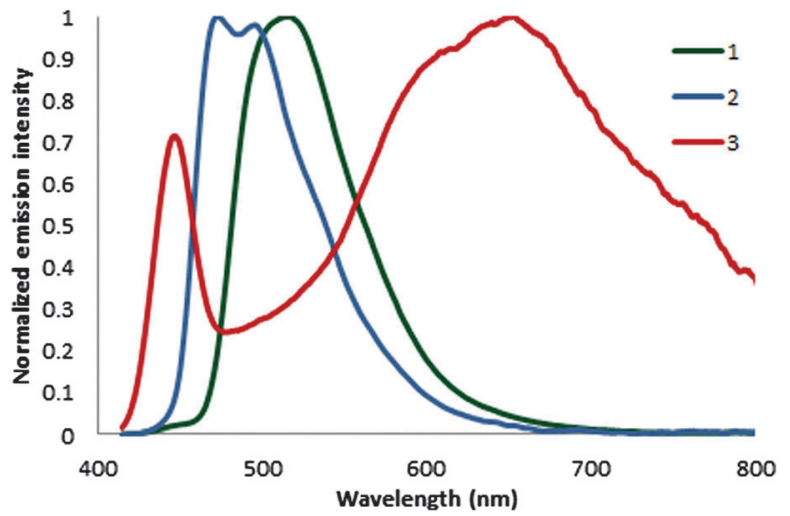

Fig. 3 Normalized emission spectra of $1-3\left(\lambda_{\text {exc }}=395 \mathrm{~nm}\right)$ recorded in degassed MeCN at $298 \mathrm{~K}$. The first band at $450 \mathrm{~nm}$ for compound 3 correspond to a Raman band of $\mathrm{MeCN}$.

corroborate these assignments. The CT emission in $\mathbf{1}$ is the result of mixed LLCT and MLCT that is mostly LLCT in nature and involves the pyridine moieties of the $\mathrm{C}^{\wedge} \mathrm{N}$ ligands while the CT emission of 3 is also mixed with almost equal LLCT and MLCT contributions that involve the pyrazine of the gpz ligand. The emission maximum of 3 is at $640 \mathrm{~nm}$, which is significantly red-shifted as compared to those of 1 and 2. With the presence of the dFMeppy ligand, the emission maximum in 2 is expectedly blue-shifted to $470 \mathrm{~nm}$. Consistent with the absorption and electrochemical data, the emission maxima for $\mathbf{1}$ and $\mathbf{2}$ are hypsochromically shifted as compared to those of $\mathbf{C 1}$ $\left(\lambda_{\max }=602 \mathrm{~nm}\right)$ and $\mathbf{C 2}\left(\lambda_{\max }=527 \mathrm{~nm}\right) .{ }^{15}$ This effect is again due to the strong $\sigma$-donating nature of the guanidyl moiety that destabilizes both the HOMO and LUMO, the latter to a greater extent resulting in a larger HOMO-LUMO gap. In the case of 3, the LUMO now resides on the guanidine-based ligand, which is significantly lower in energy due to the electron-deficient pyrazine moiety.

The photoluminescence quantum yields, $\Phi_{\mathrm{PL}}$, in degassed MeCN for 1 and 2 are $c a$. 61\%. Complex 3, by contrast is very poorly emissive $\left(\Phi_{\mathrm{PL}}=0.2 \%\right)$ due to a two-order increase in the non-radiative decay rate constant, $k_{\mathrm{nr}}$. The inference is that implicating the pyrazine-based ancillary ligand in the triplet state results in quenched emission. Emission lifetimes for $\mathbf{1}$ and 2 are 2.1 and $2.6 \mu \mathrm{s}$, respectively, and are significantly longer than that of $\mathbf{C 1}\left(\tau_{\varepsilon}=0.275 \mu \mathrm{s}\right)^{15}$ while the $\tau_{\varepsilon}$ of 3 is only $20 \mathrm{~ns}$. The conformational flexibility present in the saturated backbone of the guanidyl cycle coupled with a triplet state involving the pyrazine moiety, may be responsible for the short observed lifetime in 3. Indeed, very efficient vibrational deactivation was previously noted for $\mathrm{Ru}(\mathrm{II})$ complexes of guanidinebased ligands. ${ }^{6}$

In summary, a new class of blue-green emissive iridium(III) cationic complexes with partially saturated guanidyl-containing ancillary ligands is reported. The strong electron-donating character of the guanidyl cycle confers a very large blue shift in the emission compared to benchmark complex $\mathbf{C 1}$ while maintaining high photoluminescence quantum yields and microsecond emission lifetimes. Incorporation of a pyrazine unit in 3 results in near complete quenching of the luminescence with a concomitant red-shift of its emission wavelength. 
The overall structural, electrochemical and photophysical properties of $\mathbf{1}$ and $\mathbf{2}$ are encouraging and current efforts are underway to investigate these complexes as emissive materials in solid-state lighting applications.

The authors are grateful to the Natural Sciences and Engineering Research Council (NSERC) of Canada, le Fonds québécois de la recherche sur la nature et les technologies (FRQNT), the Centre for Self Assembled Chemical Structures (CSACS), the Centre in Green Chemistry and Catalysis (CCVC), and the Université de Montréal (UdeM) for financial support. UdeM $\mathrm{XRD}$, NMR, EA, and MS services and personnel, as well as Compute Canada, are also thanked. EZ-C acknowledges the University of St Andrews for financial support.

\section{Notes and references}

1 (a) R. D. Costa, E. Ortí, H. J. Bolink, F. Monti, G. Accorsi and N. Armaroli, Angew. Chem., Int. Ed., 2012, 51, 8178; (b) T. Hu, L. He, L. Duan and Y. Qiu, J. Mater. Chem., 2012, 22, 4206; (c) G. E. Schneider, A. Pertegás, E. C. Constable, C. E. Housecroft, N. Hostettler, C. D. Morris, J. A. Zampese, H. J. Bolink, J. M. Junquera-Hernández, E. Ortí and M. Sessolo, J. Mater. Chem. C, 2014, 2, 7047; (d) A. B. Bünzli, H. J. Bolink, E. C. Constable, C. E. Housecroft, J. M. Junquera-Hernández, N. Neuburger, E. Ortí, A. Pertegás, J. J. Serrano-Pérez, D. Tordera and J. A. Zampese, Dalton Trans., 2014, 43, 738; (e) K. Hasan, L. Donato, Y. Shen, J. D. Slinker and E. Zysman-Colman, Dalton Trans., 2014, 43, 13672.

2 (a) K. Hasan and E. Zysman-Colman, Inorg. Chem., 2012, 51, 12560-12564; (b) Y. Shinpuku, F. Inui, M. Nakai and Y. Nakabayashi, J. Photochem. Photobiol., A, 2011, 22, 203.

3 For recent review and examples see; $(a)$ K. K.-W. Lo and S. P.-Y. Li, $R S C A d v$., 2014, 4, 10560; (b) K. K.-W. Lo and K. Y. Zhang, RSC Adv., 2012, 2, 12069; (c) F. Lu and T. Nabeshima, Dalton Trans., 2014, 43, 9529; (d) Y. You, Curr. Opin. Chem. Biol., 2013, 17, 699; (e) Y. You, S. Lee, T. Kim, K. Ohkubo, W.-S. Chae, S. Fukuzumi, G.-J. Jhon, W. Nam and S. J. Lippard, J. Am. Chem. Soc., 2011, 133, 18328.

4 (a) K. Mori, J. Aoyama, M. Kawashimaa and H. Yamashita, Dalton Trans., 2014, 43, 10541; (b) D. R. Whang, K. Sakai and S. Y. Park, Angew. Chem., Int. Ed., 2013, 52, 11612; (c) S. Hansen, M.-M. Pohl, M. Klahn, A. Spannenberg and T. Beweries, ChemSusChem, 2013, 6, 92; (d) B. F. Disalle and S. Bernhard, J. Am. Chem. Soc., 2011, 133, 11819; (e) F. Gärtner, D. Cozzula, S. Losse, A. Boddien, G. Anilkumar, H. Junge, T. Schulz, N. Marquet, A. Spannenberg, S. Gladiali and M. Beller, Chem. - Eur. J., 2011, 17, 6998; $(f)$ L. L. Tinker and S. Bernhard, Inorg. Chem., 2009, 48, 10507.
5 (a) K. P. S. Zanoni, B. K. Kariyazaki, A. Ito, M. K. Brennaman, T. J. Meyer and N. Y. Murakami Iha, Inorg. Chem., 2014, 53, 4089; (b) L. He, J. Qiao, L. Duan, G. Dong, D. Zhang, L. Wang and Y. Qiu, Adv. Funct. Mater., 2009, 19, 2950; (c) G. J. Barbante, E. H. Doeven, E. Kerr, T. U. Connell, P. S. Donnelly, J. M. White, T. Lópes, S. Laird, D. J. D. Wilson, P. J. Barnard, C. F. Hogan and P. S. Francis, Chem. Eur. J., 2014, 20, 3322; (d) S. Stagni, S. Colella, A. Palazzi, G. Valenti, S. Zacchini, F. Paolucci, M. Marcaccio, R. Q. Albuquerque and L. De Cola, Inorg. Chem., 2008, 47, 10509; (e) L. He, L. Duan, J. Qiao, D. Zhang, L. Wang and Y. Qiu, Chem. Commun., 2011, 47, 6467; $(f)$ S. Ladouceur and E. Zysman-Colman, Eur. J. Inorg. Chem., 2013, 2985.

6 (a) A. K. Pal, S. Nag, J. G. Ferreina, V. Brochery, G. L. Ganga, A. Santora, S. Serroni, S. Campagna and G. S. Hanan, Inorg. Chem., 2014, 53, 1679; (b) A. K. Pal, P. D. Ducharme and G. S. Hanan, Chem. Commun., 2014, 50, 3303; (c) A. K. Pal and G. S. Hanan, Dalton Trans., 2014, 43, 6567; (d) A. K. Pal, N. Zaccheroni, S. Campagna and G. S. Hanan, Chem. Commun., 2014, 50, 6846; (e) A. K. Pal, S. Serroni, N. Zaccheroni, S. Campagna and G. S. Hanan, Chem. Sci., 2014, 5, 4800; $(f)$ A. K. Pal and G. S. Hanan, Chem. Soc. Rev., 2014, 43, 6184; $(g)$ S. Nag, J. G. Ferreira, L. Chenneberg, P. D. Ducharme, G. S. Hanan, G. L. Ganga, S. Serroni and S. Campagna, Inorg. Chem., 2011, 50, 7.

7 (a) S. H. Oakley, M. P. Coles and P. B. Hitchcock, Inorg. Chem., 2004, 43, 7564; (b) M. P. Coles, Chem. Commun., 2009, 3659; (c) M. S. Khalaf, S. H. Oakley, M. P. Coles and P. B. Hitchcock, Dalton Trans., 2010, 39, 1635.

8 (a) B. De Groot, G. S. Hanan and S. J. Loeb, Inorg. Chem., 1991, 30, 4644; (b) G. R. Giesbrecht, G. S. Hanan, J. E. Kickham and S. J. Loeb, Inorg. Chem., 1992, 31, 3286.

9 R. D. Costa, E. Ortí, H. J. Bolink, S. Graber, S. Schffner, M. Neuburger, C. E. Housecroft and E. C. Constable, Adv. Funct. Mater., 2009, 19, 3456.

10 S. Ladouceur, D. Fortin and E. Zysman-Colman, Inorg. Chem., 2010, 49, 5625 and references cited therein.

11 For overlay of experimental absorption spectra of the complexes in acetonitrile with their predicted transitions and oscillator strength, see Fig. S14-S16, ESI $\dagger$.

12 V. V. Pavlishchuk and A. W. Addison, Inorg. Chim. Acta, 2000, 298, 97.

13 (a) L. Donato, P. Abel and E. Zysman-Colman, Dalton Trans., 2013, 42, 8402; (b) J. H. van Diemen, J. G. Haasnoot, R. Hage, E. Müller and J. Reedijk, Inorg. Chim. Acta, 1991, 181, 245.

14 (a) E. Orselli, R. Q. Albuquerque, P. M. Fransen, R. Frohlich, H. M. Janssen and L. De Cola, J. Mater. Chem., 2008, 18, 4579; (b) J. M. Fernandez-Hernandez, S. Ladouceur, Y. Shen, A. Iordache, X. Wang, L. Donato, S. Gallagher-Duval, M. de Anda Villa, J. D. Slinker, L. De Cola and E. Zysman-Colman, J. Mater. Chem. $C, 2013,1,7440$.

15 S. Ladouceur, D. Fortin and E. Zysman-Colman, Inorg. Chem., 2011, 50, 11514.

16 W. H. Melhuish, J. Phys. Chem., 1961, 65, 229. 